Elsevier

CCA 03867

\title{
Glucagon and insulin response to meals in non-obese and obese Dutch women
}

\author{
Peter Hill, Luba Garbaczewski, Hans Koppeschaar, Jos H.H. Thijssen and \\ Fritz de Waard
}

Prevention and Department of Endocrinology Academisch Ziekenhuis, Utrecht (The Netherlands)

Key words: Glucagon-insulin meals; Body mass index; B-Endorphin

\section{Summary}

Many digestive complaints are associated with abnormalities in gastrointestinal peptide hormone function. To investigate the effect of obesity on the release of pancreatic peptide hormones, we have compared the release of insulin and glucagon in non-obese-obese Dutch women in response to isocaloric mixed meals and to Naloxone, an opioid antagonist.

Healthy premenopausal women who were separated into three groups based on body mass index (BMI $<23 ; 23-27,>28$ ), were fed 600 -calorie breakfasts. Higher fasting levels of plasma insulin and glucagon occurred in obese (BMI $>28)$ than lean (BMI < 23) women, while glucagon and insulin release after a high fat meal occurred in obese women. Naloxone administration in obese women decreased plasma insulin and glucagon, but in lean women, naloxone increased plasma glucagon but did not alter plasma insulin levels. Results indicate differences in opiate effects on pancreatic function in non-obese-obese women.

\section{Introduction}

A high incidence of diseases related to abnormalities in eating behaviour and digestion occur in Western societies. Two major factors, body weight and stress alter the physiological and biochemical control of digestion.

Gastric emptying is faster in the obese [1] and slower emptying occurs in patients with Anorexia Nervosa [2]. Gastric emptying time is also modified by age, meal composition [3], liquids vs. solids, and sex [4]. Stress modifies gastrointestinal transit

Correspondence to: Dr. Peter Hill, American Health Foundation, 320 East 43rd Street, New York, NY 10017, USA. 
time [5], while emotional events alter eating patterns and body mass index [6].

While the etiology of obesity remains unclear, differences in eating patterns [7], or specific cravings [8] reflect changes in the gut-CNS peptide hormones which control the absorption of nutrients. Composition of luminal nutrients per se alter absorption [9] and the release of gut-pancreatic peptide hormones [10]. Administration of glucagon causes gastric dysrhythmia [11] and decreases the secretion of gastric acid [12], while administration of B-endorphin has been reported to release insulin and glucagon from the pancreas [13] and inhibit colonic motility. Opioid peptides has been reported to increase food intake [14] while higher plasma levels have been reported in obese versus lean women [15].

Accordingly, we have studied the pancreatic peptide hormone response to isocaloric mixed-meals, and naloxone administration, an opiate antagonist, in healthy non-obese and obese Dutch women to determine whether differences occur in these women.

\section{Materials and methods}

Healthy menstruating Dutch women with regular bowel movements and free from overt digestive problems, allergies, constipation, diarrhea or endocrine dysfunction, hyperthyroid or diabetes mellitus were selected. Regular daily users of laxatives, aspirins, or ant-acid compounds or current use of medication including oral contraceptives were excluded. All studies were carried out on days 5-10 of the menstrual cycles.

The women were separated into three groups based on body mass index. Group I body mass index $(\mathrm{BMI})<23$, mean $21 \pm 0.3$; Group II BMI 23-27, mean $25 \pm 0.2$; Group III BMI $>28$, mean $31 \pm 0.6$. The mean age of the three groups was Group I $45.7 \pm 0.7$, Group II $47.5 \pm 0.6$, Group III $47.1 \pm 0.8$. The minimum number in any group was eight women.

Women were fed standardized isocaloric carbohydrate and high-fat breakfasts providing 600 calories per meal. After an overnight fast, an indwelling catheter was placed in the anticubital vein and the first blood sample taken $15 \mathrm{~min}$ later. The meal was then fed and the women allowed $15 \mathrm{~min}$ to eat the meal. Serial blood samples were taken during and after the meals.

Naloxone was administered as $5 \mathrm{mg}$ i.v. bolus $15 \mathrm{~min}$ before the meals and was infused at $5 \mathrm{mg}$ per hour for two hours starting with the meal. Naloxone studies were carried out only in women with BMI $<23$ and BMI $>28$.

Breakfast were prepared by the dietitian using customary Dutch food. The high fat breakfast, for example, consisted of bread with butter, cheese, and coffee with whole cream. The protocol was approved by the ethics committee, while informed consent was obtained.

\section{Plasma assays}

Insulin was determined by RIA using the MRC $66 / 217$ preparation as the reference standard [16] while pancreatic glucagon was determined using a RIA provided by Novo Research Institute, Bagsverd, Denmark. The inter- and intra-as- 


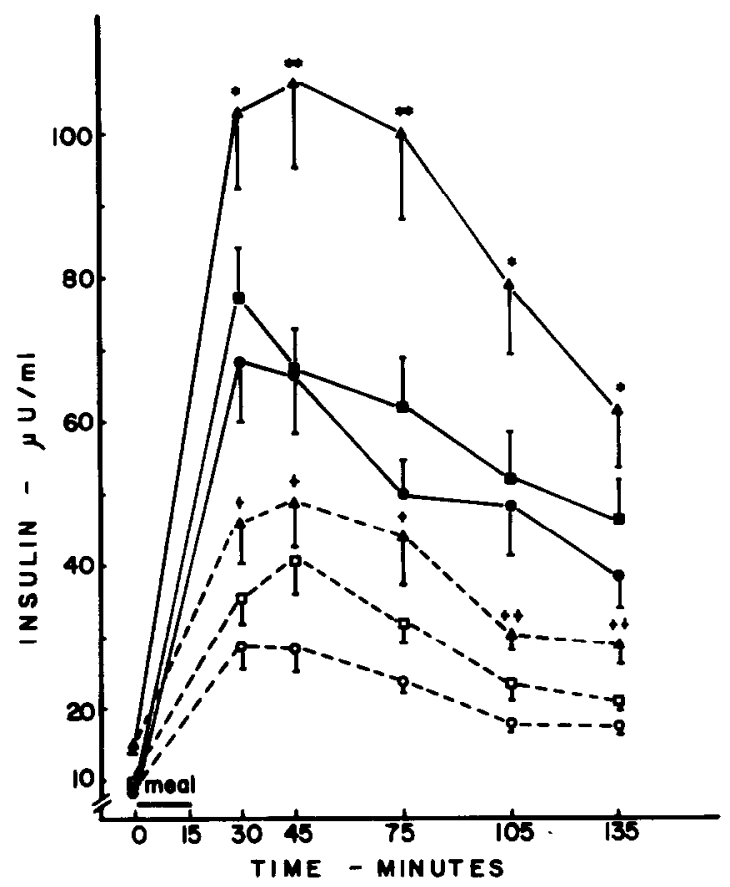

Fig. 1. Insulin response to high fat breakfast $(---)$ or a high carbohydrate breakfast $(-)$ in lean BMI <23 $(O, \bullet) n=12$; BMI 23-27 (, 口) $n=15$; obese women BMI $>28(\Delta, \Delta) n=13$. Results given as mean $\pm \mathrm{SE}^{*} p<0.05 * * p<0.01$ significantly greater in BMI $>28$ than BMI 23-27 carbohydrate breakfast or BMI $>28$ than $\mathrm{BMI}<23$ high fat breakfast, respectively.

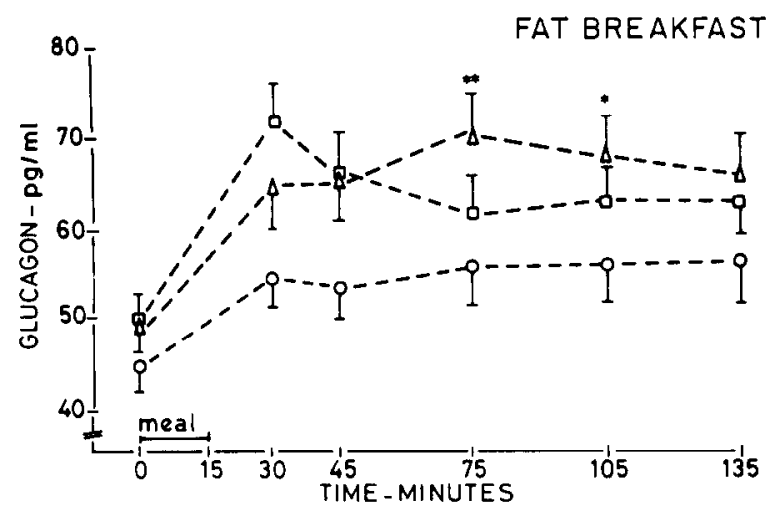

Fig. 2. Glucagon response to a high fat breakfast in women with increasing body weight. Glucagon release significantly greater in women BMI $>28(\Delta)$ compared to women BMI <23(O). No. per group as in Fig. 1. 
say coefficients of variation (CVs) were $7.0 \%$ and $4.3 \%$ and $12.7 \%$ and $11.5 \%$, respectively. B-Endorphin, was determined by RIA using an antibody with a 1\% cross reactivity with B-lipotropin (Immunonuclear Corp., Stillwater, MN, USA). The inter- and intra-assay CVs were $14.5 \%$ and $6.4 \%$, respectively, with a recovery of $88 \%$ at $5 \mathrm{pmol} / \mathrm{l}$. Basal endorphin levels obtained in 4 different days in 12 women showed a high correlation $\left(r^{2}=0.83\right)$ indicating that basal levels were highly reproducible in the same individual.

\section{Statistical analysis}

Comparison between studies of individual women was carried out using Student's paired ' $t$ ' test while responses to meals and Naloxone administration between groups was determined by comparison of the integrated area under the curves.

\section{Results}

As shown in Fig. 1, the carbohydrate breakfast released more insulin than the isocaloric fat breakfast. Although the increase in insulin correlated with increasing BMI for the carbohydrate meal, a comparable release of insulin occurred in women BMI $<23$ and 23-27.

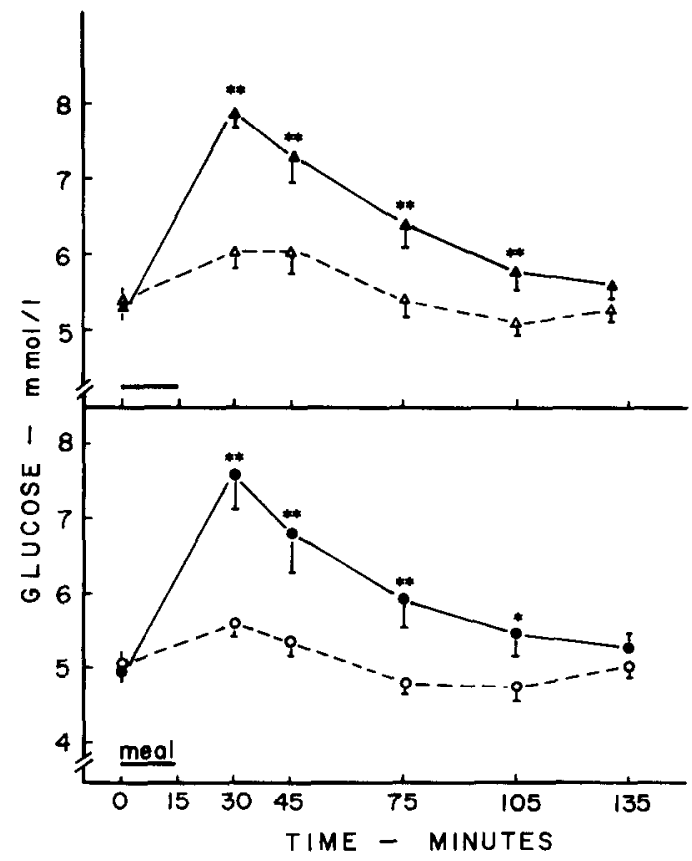

Fig. 3. Glucose response to a high fat breakfast $\left({ }_{-}-{ }_{-}\right)$or a high carbohydrate breakfast $(-\longrightarrow)$ in lean BMI $<23(0, \bullet)$ and obese BMI $>28(\Delta, \Delta)$. Significantly higher on carbohydrate breakfast. $p \leqslant 0.01$. 


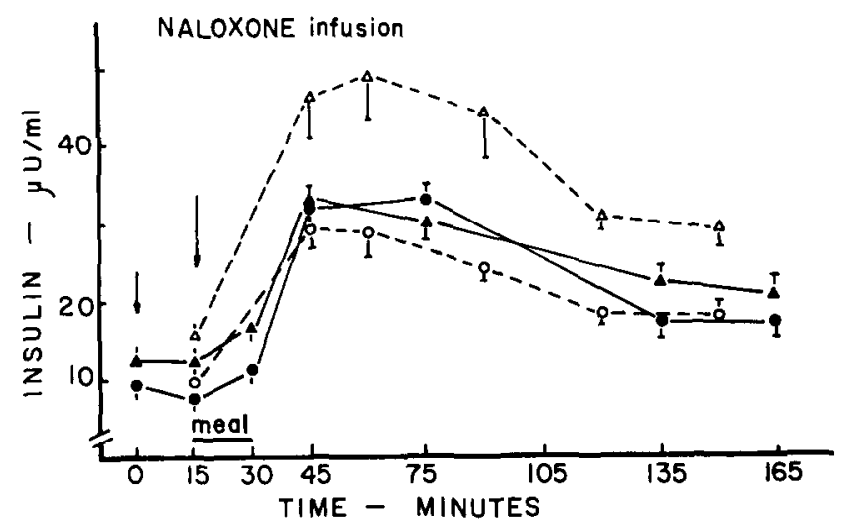

Fig. 4. Insulin response to intravenous infusion of Naloxone, $5 \mathrm{mg}$ bolus $15 \mathrm{~min}$ before the meal and

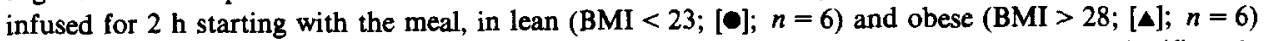
women fed a high fat breakfast. Results given as mean \pm SE. Insulin release in obese women significantly reduced by naloxone infusion ${ }^{* *} p \leqslant 0.01$, area under curve.

The high-fat breakfast caused a greater and more prolonged release of glucagon in women BMI $>28$ (Fig. II). The increase in plasma glucose was significantly higher with the carbohydrate breakfast, but the increase in glucose levels after the high fat meal was similar in obese (BMI $>28$ ) than lean (BMI <23) women (Fig. 3).

To prevent overlapping of pancreatic response to meals in the intermediate group of women (BMI 23-27), Naloxone infusion was given only to lean $(\mathrm{BMI}<23)$ and

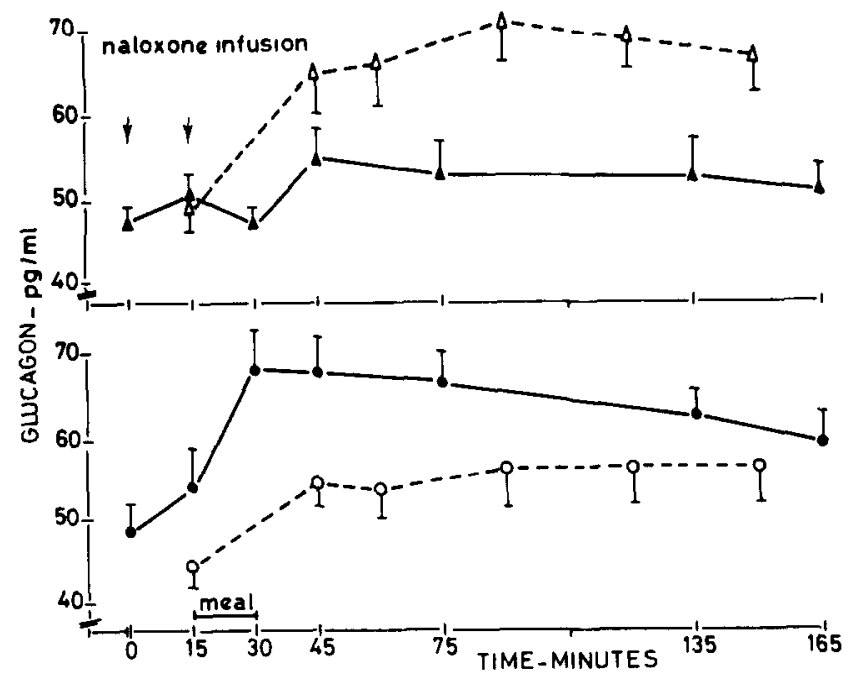

Fig. 5. Glucagon response to intravenous infusion of naloxone as described in Fig. 4. Glucagon release in women BMI $>28$ significantly decreased by naloxone following a high fat breakfast, while in women $\mathrm{BMI}<23$ glucagon release was significanlty increased as determined by area under curve. $p \leqslant 0.01$. 


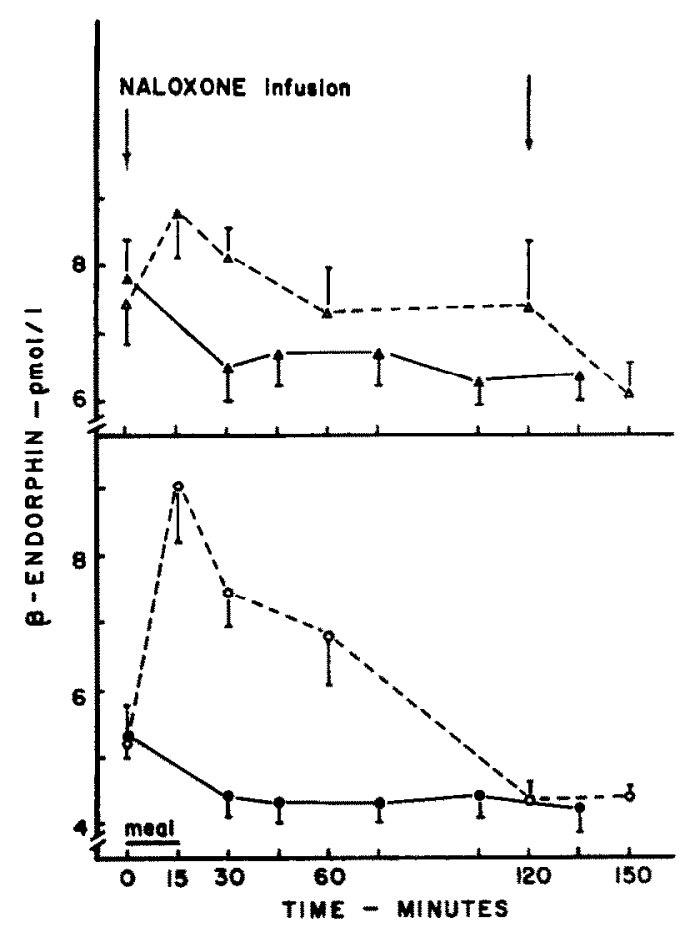

Fig. 6. Effect of Naxolone administration on plasma B-endorphin in lean, BMI 23 and obese, BMI 28 women fed a high fat breakfast. A significant increase in plasma-endorphin occurred in the lean women administered Naxolone. $p \leqslant 0.01$ area under curve details Fig. 4.

obese $(\mathrm{BMI}>28)$ women. Naloxone administration decreased plasma insulin only in obese women (BMI $>28$ ) (Fig. 4), while plasma glucagon levels were decreased in obese women but increased in lean (BMI <23) women (Fig. 5). Naloxone infusion delayed, for $30 \mathrm{~min}$, the increase in plasma glucose after a high fat breakfast in lean and obese women.

As previously reported plasma B-endorphin levels were higher in obese versus lean women, while neither the high fat or carbohydrate breakfast altered plasma B-endorphin levels.

Infusion of Naloxone caused a significant increase in plasma B-endorphin in lean $($ BMI $<23$ ) but not obese (BMI $>28$ ) women (Fig. 6).

\section{Discussion}

Although the increase in plasma insulin was less after a high fat versus a high carbohydrate breakfast, an increased release of insulin occurred with both breakfasts with increasing body mass index. Similarly, a greater increase in plasma glucagon levels occurred in obese vs. lean women. Interestingly an increase in plasma B-endorphin levels occurred only in obese women administered naloxone and fed a high-fat meal. 
Since insulin induced hypoglycemia is associated with an increase of glucagon and as oral glucose administration decreases glucagon, Hatfield et al [17] suggested that the balance between alpha and beta cell activity in the pancreas was related to carbohydrate intake with a preference for insulin rather than glucagon release. Furthermore, insulin-glucagon activity is affected by meal composition [10] while in the obese, glucagon may depend on the interaction of luminal protein and glucose with a loss of insulin control of free fatty acid metabolism [18].

High-plasma levels of glucagon in obese compared with lean women have been reported previously by some $[19,20]$ but not all studies [21,22], while Alford et al [19] have reported a greater release of glucagon in obese women after oral glucose administration.

Regarding the relationship of opioid peptides and the release of pancreatic glucagon and insulin, B-endorphin administration have been reported to release insulin and glucagon [13,23], although Naloxone administration failed to block insulin secretion [24].

It should be noted that B-endorphin has been reported in D-cells of the pancreas $[25,26]$ while glucagon and endorphin immunoreactivity have been reported in alpha cells of the pancreas [27].

In obese women, Naloxone administration significantly decreased the secretion of insulin and glucagon, while in lean women fed a high-fat breakfast, glucagon secretion increased but insulin secretion was unaltered.

While all the lean women in this study menstruated regularly, it has been reported that in patients with Anorexia Nervosa that Naloxone increased plasma glucagon levels and did not alter plasma insulin levels [28]. Lower plasma levels of B-endorphin have also been reported in Anoretic patients.

Lower plasma levels of B-endorphin in lean (BMI <23) women and the significant increase in plasma B-endorphin in lean women fed a high fat breakfast and administered Naloxone suggests that in lean women B-endorphin or mu receptors are not implicated in insulin release, as reported by Morley et al [24].

Alternatively, in lean women fed a high fat meal and administered Naloxone the increased glucagon release implies an inhibitory role of opioid peptides.

Opioid peptide control of food intake [14] and carbohydrate craving by the obese [8] form part of the eating patterns in obese subjects; patterns which are also modulated by cephalic-vagal stimulation involving insulin secretion in the obese [29].

In the obese, the prolonged higher plasma glucagon levels and greater glucagon response to a high fat meal may lead to a higher incidence of gastric dysrhythmias and/or higher gastric acid secretion. This study clearly indicates the importance of mixed meals on the pancreatic release of peptide hormones and the interaction with body weight and their possible relationship with digestive dysfunction.

\section{Acknowledgement}

The investigation was carried out under an Eleanor Roosevelt International Cancer Fellowship supported by the International Union Cancer Control, Geneva, Switzerland. 


\section{References}

1 Wright RA, Krinsky S, Fleeman C, Trujillo T, Teague E. Gastric Emptying and Obesity. Gastroenterol 1983;84:747-751.

2 Dubois A, Gross HA, Ebert MH, Castell DO. Altered gastric emptying and secretion in primary anorexia nervosa. Gastroenterol, 1979;77:319-323.

3 Holgate AM, Read NW. Effect of ileal infusion of intralipid on gastrointestinal transit, ileal flow rate and carbohydrate absorption in humans after ingestion of a liquid meal. Gastroenterol 1985;88:1005-1011.

4 Notivol R, Carrio I, Cano L, Estorch M, Vilardell F. Gastric emptying of solid and liquid meals in healthy young subjects. Scand J Gastroenterol 1984;19:1107-1113.

5 Longmore J, Nix S, Simms N, Swallow K, Weller J. Psychological stress and the passage of a standard meal through the stomach and small intestine in man. Gut 1983;34:236-240.

6 Van Strein T, Rookus MA, Bergers GPA, Frijters Jer DeFares PB. Life events, emotional eatıng and change in body mass index. Int $J$ Obesity 1986;10:29-35.

7 Logue AW, Smith ME. Predictors of food preferences in adult humans. Appetite 1986;7:109-125.

8 Wurtman RJ. Behavioural efforts of nutrients. Lancet 1983;1:1145-1147.

9 Johansson C. Studies of gastrointestinal interaction. VII. Characteristics of the absorption pattern of sugar, fat and protein from the composite meals in man. A quantitative study. Scand J Gastroenterol $1975 ; 10: 33-42$.

10 Schusdziarra V, Holland A, Maier V, Pfeiffer EF. Effect of naloxone on pancreatic and gastric endocrine function in response to carbohydrate and fat rich test meals. Peptides 1984;5:65-71.

11 Abell TL, Malagelada JR. Glucagon-evoked gastric dysrhythmias in humans shown by an improved electrogastrographic technique. Gastroenterol 1985;88:1932-1940.

12 Christiansen J, Holst JJ, Kalaja E. Inhibition of gastric acid secretion in man by exogenous and endogenous pancreatic glucagon. Gastroenterol 1976;70:688-697.

13 Feldman M, Kiser RS, Unger RH, Li CH. Beta-Endorphin and the endocrine pancreas. N Engl J Med 1983;308:349-353.

14 Morley JE. Neuroendocrine effects of endogenous opioid peptides in human subjects: a review. Psychoneuroendocrinol 1983;8:361-379.

15 Givens JR, Wiederman E, Anderson RN, Kitabchi AE. B-Endorphin and B-lipotropin plasma levels in hirsute women: correlation with body weight. J Clin Endocrinol Metab 1980;50:975-978.

16 Kortland $\mathrm{W}$. Thijsen $\mathrm{JHH}$. Variation among insulin radioimmunoassay is mainly a matter of standardization. Clin Chem 1983;29:1689.

17 Hatfield HH, Banasiak MF, Driscoll T, Kim HJ, Kalkhoff RK. Glucose suppression of glucagon: relationship to pancreatic beta cell function. J Clin Endocrinol Metab 1977;44:1080-1087.

18 Golay A, Swislocke ALM, Chen YDL, Jaspan JH, Reaven GH. Effect of obesity on ambient plasma glucose, free fatty acid, insulin, growth hormones and glucagon concentration. J Clin Endocrinol Metab 1986;63:481-484.

19 Alford FP, Zimmet P, Chisholm DJ, Whitehouse S. Influence of obesity on basal glucagon levels in non-diabetic and diabetic nauruans. Clin Endocrinol 1983;19:721-725.

20 Hansen BC, Jen KC, Pek SB, Wolfe RA. Rapid oscillations in plasma insulin, glucagon and glucose in obese and normal weight humans. J Clin Endocrinol. Metab 1982;54:785-792.

21 Santiago JC, Haymond MW, Clarke WL, Pagliara AS. Glucagon, Insulin and glucose responses to physiologic testing in normal and massively obese adults. Metab 1977;26:1115-1127.

22 Gossain VV, Srivastava L, Rovner DR, Turek D. Plasma glucagon in simple obesity: effect of exercise. Am J Med Sci 1983;286:4-10.

23 Reid RL, Yen SSC. B-Endorphin stimulates the secretion of insulin and glucagon in humans. J Clin Endocrinol Metab 1981;52:592-594.

24 Morley JE, Baranetsky NG, Wingert TD, Carlson HE, Hershman JM, Melmed S, Levin SR, Jamison KR, Weitzman R, Chang RI, Varner AA. Endocrine effects of naloxone-induced opiate receptor blockade. J Clin Endocrinol Metab 1980;50:251-257.

25 Kyriakides M, Silverstone T, Jeffcoate W, Laurance B. Effect of naloxone on hyperphagia in Prader-Willi syndrome. Lancet 1980;1:876. 
26 Bruni JF, Watkins Wb, Yen SSC. B-Endorphin in the human pancreas. J Clin Endocrinol Metab 1979;49:649-651.

27 Grube D, Voigt KH, Weber E. Pancreatic glucagon cells contain endorphin-like immunoreactivity. Histochemistry 1978;59:75-79.

28 Moore R, Mills IH, Forster A. Naloxone in the treatment of anorexia nervosa: effect of weight gain and lipolysis. J R Soc Med 1981;74:129-131.

29 Taylor JL, Feldman M. Effect of cephalic-vagal stimulation on insulin, gastric inhibitory polypeptide and pancreatic polypeptide release in humans. J Clin Endocrinol Metab 1982;55:1114-1117. 